
\title{
3 Research Square \\ Anti-Inflammatory Effect of Cross-Linked Hyaluronic Acids in Osteoarthritic Knee, Detected by Ultrasonography
}

\section{Saradej Khuangsirikul ( $\sim$ ksaradej@yahoo.com )}

Phramongkutklao College of Medicine https://orcid.org/0000-0003-4256-5432

\section{Apiwat Yuwapan}

Phramongkutklao College of Medicine

Danai Heebthamai

Phramongkutklao College of Medicine

Thanainit Chotanaphuti

Phramongkutklao College of Medicine

Research article

Keywords: Cross-linked hyaluronic acid, Synovial hypertrophy, Knee osteoarthritis, Ultrasonography, Synovial thickness

Posted Date: June 23rd, 2020

DOI: https://doi.org/10.21203/rs.3.rs-37185/v1

License: (c) (i) This work is licensed under a Creative Commons Attribution 4.0 International License. Read Full License 


\section{Abstract}

Background: Synovial hypertrophy is one of the pathological characteristics of knee osteoarthritis (OA), which is associated with the inflammation process and disease severity. Ultrasonography (US) is a practical tool to monitor disease progression and the response to treatment. Intra-articular hyaluronic acid (IAHA) is one of the commonly-used alternative treatments for knee OA. In this study, we used US to assess the effects of cross-linked hyaluronic acid, in terms of minimizing inflammation, by comparing synovial thickness before and after IAHA.

Methods: Seventy-nine OA patients (107 knees, KL II-III and KL IV with surgery refusal) were treated with cross-linked IAHA and underwent US before IAHA at 4-week and 3-month follow-up visits after injection. Comparisons of synovial thickness before and after injection were analyzed. Clinical outcomes were also evaluated by the recording of the visual analog scale for pain (pain VAS).

Results: The overall synovial thickness was significantly decreased after IAHA at 4 weeks $(p=0.01)$. The thickness was significantly reduced in KL II $(p=0.01)$, but not significant in KL III and IV ( $p=0.096$ and 0.083 , respectively). In KL IV, the thickness was significantly increased at 3 months after IAHA $(p=0.02)$. The pain VAS improved gradually at 4 weeks and 3 months after IAHA, significantly $(p<0.001)$ in all $\mathrm{KL}$ stages.

Conclusion: Cross-linked hyaluronic acid injection provided pain relief in all KL stages at 4 weeks and lasted at least 3 months. However, its anti-inflammation action was temporary and predominated only in patients with early-stage OA knee. Concerning inflammation as a major risk factor for OA progression, adjunct intervention after IAHA should be added to enhance the therapeutic effect and prevent further joint destruction.

IRBRTA: R074h/62

\section{Background}

The synovium of the osteoarthritic knee shows significant changes, even before visible cartilage degeneration has occurred, with infiltration of mononuclear cells, thickening of the synovial lining layer and the production of inflammatory cytokines. ${ }^{1}$ Several cohort studies have shown a positive correlation between synovial pathology and disease progression. ${ }^{2-4}$ Therefore, synovitis or synovial hypertrophy have been proven to be a potential biomarker for the inflammatory process, disease severity, and therapeutic response in osteoarthritis $(\mathrm{OA})$ of the knee. ${ }^{5}$

Ultrasonography (US) has been widely used to detect synovial hypertrophy and effusion in OA knees. Compared to clinical examination, US is more sensitive and well correlated with the histological findings. ${ }^{6-9}$ Some studies reported equivalent sensitivity of synovitis detection by US compared to magnetic resonance imaging (MRI). ${ }^{10,11}$ Moreover, this tool is non-invasive, relatively inexpensive, and involves a short examination time, as well as having no radiation burden and good patient 
acceptability. ${ }^{12}$ Synovial thickness, which can be detected by US, is a practical biomarker to monitor inflammation, disease progression and therapeutic response to interventions.

Among the various treatments for osteoarthritis, viscosupplement with intra-articular injection of hyaluronic acid (IAHA) has been widely and successfully used. IAHA is a less invasive intervention that may be an effective alternative treatment instead of surgery. The effects of IAHA have been reported to not only improve the viscoelasticity of synovial fluid, but also minimize inflammation and disease progression. ${ }^{13,14}$ However, few studies have been conducted about cross-linked hyaluronic acid with higher molecular weight concerning its mechanisms and effects, especially in terms of anti-inflammation and pain control.

The purpose of this study was to evaluate the anti-inflammation effect of cross-linked hyaluronic acid injection in patients with OA knees, as well as compare the synovial thickness detected by US between before and after injection. The pain control effect was also monitored for 3 months.

\section{Methods}

Our institutional ethics committee approved this study prior to enrollment of the first patient (R074h/62). All patients provided written informed consent before participation in this trial. This study was designed as a cohort study.

Patients who visited the orthopedic out-patient clinic at Phramongkutklao Hospital from October 2019 to November 2019 with a chief complaint of knee pain were evaluated. The inclusion criteria were unilateral or bilateral knee OA according to 2016 American College of Rheumatology (ACR) clinical classification criteria for early diagnosis of knee $\mathrm{OA}^{15}$ and dissatisfaction with conservative treatment or an inability to take analgesic medication with the following condition; knee OA with Kellgren-Lawrence (KL) II-III, KL IV with refusal for surgery, contraindication for nonsteroidal anti-inflammatory drugs (NSAIDs) or contraindication for surgery. ${ }^{13}$ The exclusion criteria comprised patients who had a history that contributed to secondary knee $\mathrm{OA}$, such as post-infection or inflammatory joint disease, viscosupplement treatment within the previous 6 months, intra-articular corticosteroid injection within the previous 3 months or hypersensitivity to hyaluronic acid.

All of the patients underwent US measurement for synovial thickness before intra-articular injection of cross-linked HA, at 4 weeks, and 3 months after injection. Standing knee radiographs (anteroposterior and lateral views) were applied to classify disease severity with $\mathrm{KL}$ classification. ${ }^{16}$

An ultrasonogram machine (GE Healthcare model LOGIQ® e); preset: musculoskeletal - knee in B mode, $12 \mathrm{~L}-\mathrm{RS}$ wideband linear probe $(12-\mathrm{MHz})$ was used. The patients were set in a supine position on an examination table with knees maintained in a flexed but relaxed position at 30 degrees. (Fig. 1) A midline scanning technique was used by vertically applying a linear probe at just proximal to the superior pole of the patella. ${ }^{17-19}$ The quadriceps were identified as parallel lines of muscle fibers originating from the 
superior pole of the patella. Suprapatellar pre-femoral fat pad, which would be identified as a heterogenous fatty streak, was located just proximally to the anterior region of the femoral condyles. The homogenous echoic layer of tissue overlying the fat pad was the synovium. ${ }^{20,21}$ The thickest part of the synovium was measured in millimeters to one decimal. (Fig. 2)

All patients received a single intra-articular injection of cross-linked hyaluronic acid; Hyruan ONE (LG Chem, Ltd. Jeollabuk-Do, Republic of Korea). Injection was performed in a supine position. The knee was flexed approximately 90 degrees and prepared in a sterile fashion, after which $2 \mathrm{~mL}$ of $2 \%$ lidocaine hydrochloride with 1:80,000 epinephrine was infiltrated into the skin and subcutaneous tissue at the lateral soft spot of the knee joint just inferior to the lower pole of the patella with a 21-gauge needle. The accuracy of the injection was assessed by an unobstructed injection of lidocaine into the knee joint. In cases of joint effusion, the fluid would be aspirated into a separate syringe. The same needle was left in place and then a syringe prefilled with $60 \mathrm{mg} / 3 \mathrm{~mL}$ of cross-linked HA was injected. ${ }^{22}$ All patients were under the same post-injection pain control protocol with a prescription of tramadol and acetaminophen. The patients were advised not to take any other medications relevant to the treatment of the knee or arthritis.

\section{Statistical analysis}

Synovial thickness, detected by US measurement of the knee OA patients in each KL classification, was recorded as the baseline characteristic before IAHA. At 4 weeks and 3 months after injection, the US measurements were repeated to observe changes in the synovial thickness. Knee pain was also evaluated at every visit by recording the visual analog scale for pain (pain VAS).

All data were given as means \pm standard deviation (SD). Statistical comparisons were performed using paired Student's t-test for comparison of synovial thickness before and after IAHA. The synovial thickness changes in different groups of knee OA patients, according to KL classification, were assessed by unpaired t-test. A significant level was $p$-value $<0.05$. Statistical analysis was performed with STATA/MP12.

\section{Results}

Seventy-nine participating patients with 107 knees diagnosed as osteoarthritis were included in this study. The demographic data of the subjects are described in Table 1. 
Table 1

Demographic data

\begin{tabular}{|ll|}
\hline Characteristic & Data \\
\hline Sex, N (\%) & \\
\hline Male & $21(26.6 \%)$ \\
\hline Female & $58(73.4 \%)$ \\
\hline KL stage, N (\%) & \\
\hline I & $0(0 \%)$ \\
\hline II & $43(40 \%)$ \\
\hline III & $49(45 \%)$ \\
\hline IV & $15(15 \%)$ \\
\hline Age (years) & $64.62 \pm 9.21$ (range, 44-87) \\
\hline Weight $(\mathrm{kg})$ & $66.68 \pm 12.90$ (range, 42-103) \\
\hline Height $(\mathrm{cm})$ & $158.75 \pm 7.40$ (range, 144-178) \\
\hline BMI (kg/m²) & $26.38 \pm 4.30$ (range, 19.17-38.86) \\
\hline
\end{tabular}

The mean (SD) synovial thickness of all knee joints decreased significantly at 4 weeks after IAHA ( $p=$ 0.01). (Table 2) At 3 months, the mean (SD) synovial thickness of all knee joints increased markedly from $2.28 \mathrm{~mm}(0.76)$ to $2.41 \mathrm{~mm}(0.77)(p=0.047)$.

Table 2

Comparison of synovial thickness before IAHA, 4 weeks and 3 months after injection

\begin{tabular}{|lllll|}
\hline & Mean \pm SD* & Minimum & Maximum & p-value \\
\hline 1st visit & $2.28 \pm 0.76$ & 1.00 & 5.10 & 0.01 \\
\cline { 1 - 4 } 4 weeks after IAHA & $2.20 \pm 0.83$ & 1.00 & 5.10 & \\
\cline { 1 - 4 } 1st visit & $2.28 \pm 0.76$ & 1.00 & 5.10 & \multirow{2}{*}{0.047} \\
\cline { 1 - 3 } 3 months after IAHA & $2.41 \pm 0.77$ & 1.20 & 5.10 & \\
\hline * Synovial thickness $(\mathrm{mm})$ & & & \\
\hline
\end{tabular}

Considering the different groups of knee OA, only the synovial thickness in the KL II group decreased significantly at 4 weeks after IAHA but was not different at 3 months after IAHA. The synovial thickness in the KL III group was not significantly different at either 4 weeks or 3 months after IAHA. In the KL IV 
group, the synovial thickness was not significantly different at 4 weeks after IAHA, while there was a significant increase at 3 months after IAHA. (Table 3 and Fig. 3)

Table 3

Synovial thickness in different groups of knee OA

\begin{tabular}{|c|c|c|c|c|c|c|c|}
\hline & & Mean $\pm S D *$ & Median & Min & Max & $\begin{array}{l}\text { p-value } \\
\text { 1st vs. } 4 \text { wk }\end{array}$ & $\begin{array}{l}\text { p-value } \\
\text { 1st vs. } 3 \mathrm{mo}\end{array}$ \\
\hline \multirow[t]{3}{*}{ KL II } & 1st visit & $2.02 \pm 0.67$ & 1.85 & 1.00 & 3.70 & \multirow[t]{3}{*}{0.01} & \multirow[t]{3}{*}{0.582} \\
\hline & 4 weeks & $1.88 \pm 0.64$ & 1.70 & 0.80 & 3.60 & & \\
\hline & 3 months & $2.10 \pm 0.62$ & 2.10 & 1.20 & 3.60 & & \\
\hline \multirow[t]{3}{*}{ KL III } & 1st visit & $2.40 \pm 0.75$ & 2.20 & 1.20 & 4.90 & \multirow[t]{3}{*}{0.096} & \multirow[t]{3}{*}{0.127} \\
\hline & 4 weeks & $2.34 \pm 0.87$ & 2.20 & 1.00 & 4.90 & & \\
\hline & 3 months & $2.62 \pm 0.77$ & 2.40 & 1.50 & 5.00 & & \\
\hline \multirow[t]{3}{*}{ KL IV } & 1st visit & $2.75 \pm 0.86$ & 2.40 & 1.80 & 5.10 & \multirow[t]{3}{*}{0.083} & \multirow[t]{3}{*}{0.020} \\
\hline & 4 weeks & $2.80 \pm 0.84$ & 2.45 & 1.70 & 5.10 & & \\
\hline & 3 months & $2.81 \pm 0.88$ & 2.50 & 1.90 & 5.10 & & \\
\hline
\end{tabular}

The overall pain VAS was significantly decreased after IAHA at 4 weeks and 3 months follow-up $(p<$ 0.001). (Table 4)

Table 4

Comparison of visual analog scale for pain before and after IAHA

\begin{tabular}{|c|c|c|c|c|}
\hline & $\begin{array}{l}\text { Pain VAS } \\
\text { Mean } \pm \text { SD }\end{array}$ & $\begin{array}{l}\text { p-value } \\
\text { 1st vs. } 4 \text { wk }\end{array}$ & $\begin{array}{l}\text { p-value } \\
\text { 1st vs. } 3 \text { mo }\end{array}$ & $\begin{array}{l}\text { p-value } \\
4 \text { wk vs. } 3 \text { mo }\end{array}$ \\
\hline $1 \mathrm{st}$ visit & $4.9 \pm 1.39$ & \multirow[t]{3}{*}{$<0.001$} & \multirow[t]{3}{*}{$<0.001$} & \multirow[t]{3}{*}{$<0.001$} \\
\hline 4 weeks & $3.13 \pm 1.49$ & & & \\
\hline 3 months & $1.9 \pm 1.55$ & & & \\
\hline
\end{tabular}

The pain VAS in different groups of knee OA at 4 weeks and 3 months after IAHA were also significantly decreased. (Table 5) 
Table 5

Comparison of visual analog scale for pain in different groups of knee OA after IAHA

\begin{tabular}{|c|c|c|c|c|c|}
\hline & & $\begin{array}{l}\text { Pain VAS } \\
\text { Mean } \pm \text { SD }\end{array}$ & $\begin{array}{l}\text { p-value } \\
\text { 1st vs. } 4 \text { wk }\end{array}$ & $\begin{array}{l}\text { p-value } \\
\text { 1st vs. } 3 \text { mo }\end{array}$ & $\begin{array}{l}\text { p-value } \\
4 \text { wk vs. } 3 \text { mo }\end{array}$ \\
\hline \multirow[t]{3}{*}{ KL II } & 1st visit & $4.84 \pm 1.35$ & \multirow[t]{3}{*}{$<0.001$} & \multirow[t]{3}{*}{$<0.001$} & \multirow[t]{3}{*}{$<0.001$} \\
\hline & 4 weeks & $3.29 \pm 1.33$ & & & \\
\hline & 3 months & $1.9 \pm 1.57$ & & & \\
\hline \multirow[t]{3}{*}{ KL III } & 1st visit & $5.08 \pm 1.53$ & \multirow[t]{3}{*}{$<0.001$} & \multirow[t]{3}{*}{$<0.001$} & \multirow[t]{3}{*}{$<0.001$} \\
\hline & 4 weeks & $2.84 \pm 1.3$ & & & \\
\hline & 3 months & $1.88 \pm 1.16$ & & & \\
\hline \multirow[t]{3}{*}{ KL IV } & 1st visit & $4.86 \pm 1.41$ & \multirow[t]{3}{*}{0.009} & \multirow[t]{3}{*}{$<0.001$} & \multirow[t]{3}{*}{0.003} \\
\hline & 4 weeks & $3.57 \pm 1.83$ & & & \\
\hline & 3 months & $2.29 \pm 2.2$ & & & \\
\hline
\end{tabular}

\section{Discussion}

Current studies on knee OA treatment tend to be mainly based on clinical outcomes such as knee pain or functional improvement, but well-designed studies should also be conducted with intra-articular biomarkers, which may indicate long-term treatment results.

IAHA is known to have clinical effects that can decrease the pain related to knee OA. Similarly, we found in our study that cross-linked IAHA provided pain relief in all KL stages at 4 weeks and lasted at least 3 months. Moreover, our study also evaluated the intra-articular biomarker, which comprised synovial thickness measured by US as well. Even though the role of US in detecting synovitis (synovial hypertrophy or synovial thickness) is well known, it is difficult to establish a cut-off between healthy synovial thickness and synovitis in patients with knee OA. Recent studies have suggested that synovial thickness greater than $2 \mathrm{~mm}$ was well-correlated with inflammation and disease severity. ${ }^{23,24}$ In our study, the results showed that IAHA has a temporary effect of inflammatory reduction, especially in patients with early-stage knee OA. In the advanced stage of knee OA, the synovium was thicker than early-stage $\mathrm{OA}$ and showed no response to IAHA.

Inflammation is known to be a major risk of knee OA and disease progression. Although the IAHA caused significantly decreased inflammation in the early-stage knee OA patients, our study showed its effect for a short period (4 weeks), so we suggest that all knee OA patients should add any adjunct medication or intervention to prevent further joint destruction and structural damage. 
Cross-linked IAHA showed a longer effect of pain reduction, but the anti-inflammatory effect was limited. Therefore, monitoring the treatment response for knee OA with pain symptom or function might not be appropriate or sufficient. The evaluation of biomarkers, such as synovitis, could be useful and more reliable.

There were some limitations in our study. Firstly, there was no placebo group, so it cannot be ruled out that IAHA has superior efficacy compared with a placebo injection. Secondly, the follow-up period was relatively short. Long-term results should be evaluated in future research. Third, many patients in this study had early and moderate OA (KL II and III), while a small portion of the sampling had advanced OA (KL IV).

\section{Conclusion}

Cross-linked IAHA had a temporary anti-inflammatory effect in the early stage of knee OA, supported by synovial thickness that was decreased only in $\mathrm{KL}$ II at 4 weeks after injection. Concerning inflammation as a major risk factor for OA progression, adjunct intervention after IAHA should be added to enhance the therapeutic effect and prevent further joint destruction.

\section{Abbreviations}

OA: osteoarthritis, US: ultrasonography, MRI: magnetic resonance imaging, IAHA: intra-articular hyaluronic acid, ACR: American College of Rheumatology, KL: Kellgren-Lawrence, NSAIDs: nonsteroidal antiinflammatory drugs, VAS: visual analogue scale, SD: standard deviation

\section{Declarations}

\section{Ethics approval and consent to participate:}

Phramongkutklao College of Medicine institutional ethics committee approved this study prior to enrollment of the first patient (IRBRTA: R074h/62). All patients provided written informed consent before participation in this trial.

\section{Consent for publication:}

Not applicable

\section{Availability of data and material:}

The datasets used and/or analyzed during the current study are available from the corresponding author on reasonable request. 


\section{Competing interests:}

The authors declare that they have no competing interests.

\section{Funding:}

The authors declare that they have no funding.

\section{Authors' contributions:}

KS analyzed, interpreted the patient data and was a major contributor in writing the manuscript. YA analyzed, interpreted the patient data and prepared a draft manuscript. HD analyzed and interpreted the patient data. CT reviewed and edited a manuscript. All authors read and approved the final manuscript.

\section{Acknowledgements:}

Not applicable

\section{References}

1. Mathiessen A, Conaghan PG. Synovitis in osteoarthritis: current understanding with therapeutic implications. Arthritis research \& therapy. 2017 Dec 1;19(1):18.

2. Roemer FW, Guermazi A, Felson DT, Niu J, Nevitt MC, Crema MD, Lynch JA, Lewis CE, Torner J, Zhang Y. Presence of MRI-detected joint effusion and synovitis increases the risk of cartilage loss in knees without osteoarthritis at 30-month follow-up: the MOST study. Annals of the rheumatic diseases. 2011 Oct 1;70(10):1804-9.

3. Atukorala I, Kwoh CK, Guermazi A, Roemer FW, Boudreau RM, Hannon MJ, Hunter DJ. Synovitis in knee osteoarthritis: a precursor of disease?. Annals of the rheumatic diseases. 2016 Feb 1;75(2):3905.

4. Conaghan PG, D'agostino MA, Le Bars M, Baron G, Schmidely N, Wakefield R, Ravaud P, Grassi W, Martin-Mola E, So A, Backhaus M. Clinical and ultrasonographic predictors of joint replacement for knee osteoarthritis: results from a large, 3-year, prospective EULAR study. Annals of the rheumatic diseases. 2010 Apr 1;69(4):644-7.

5. Attur M, Samuels J, Krasnokutsky S, Abramson SB. Targeting the synovial tissue for treating osteoarthritis (OA): where is the evidence?. Best Practice \& Research Clinical Rheumatology. 2010 Feb 1;24(1):71-9.

6. Karim Z, Wakefield RJ, Quinn M, Conaghan PG, Brown AK, Veale DJ, Connor PO, Reece R, Emery P. Validation and reproducibility of ultrasonography in the detection of synovitis in the knee: a 
comparison with arthroscopy and clinical examination. Arthritis \& Rheumatism: Official Journal of the American College of Rheumatology. 2004 Feb;50(2):387-94.

7. Ulaşli AM, Yaman F, Dikici Ö, Karaman A, Kaçar E, Demirdal ÜS. Accuracy in detecting knee effusion with clinical examination and the effect of effusion, the patient's body mass index, and the clinician's experience. Clinical rheumatology. 2014 Aug 1;33(8):1139-43.

8. Walther M, Harms H, Krenn V, Radke S, Faehndrich TP, Gohlke F. Correlation of power Doppler sonography with vascularity of the synovial tissue of the knee joint in patients with osteoarthritis and rheumatoid arthritis. Arthritis \& Rheumatism: Official Journal of the American College of Rheumatology. 2001 Feb;44(2):331-8.

9. Labanauskaite G, Sarauskas V. Correlation of power Doppler sonography with vascularity of the synovial tissue. Medicina. 2003;39(5):480-3.

10. Tarhan S, Unlu Z. Magnetic resonance imaging and ultrasonographic evaluation of the patients with knee osteoarthritis: a comparative study. Clinical rheumatology. 2003 Sep 1;22(3):181-8.

11. Aleo E, Barbieri F, Sconfienza L, Zampogna G, Garlaschi G, Cimmino MA. Ultrasound versus low-field magnetic resonance imaging in rheumatic diseases: a systematic literature review. Clinical and experimental rheumatology. 2014;32(1 Suppl 80):S91-8.

12. lagnocco A. Imaging the joint in osteoarthritis: a place for ultrasound?. Best Practice \& Research Clinical Rheumatology. 2010 Feb 1;24(1):27-38.

13. Evanich JD, Evanich CJ, Wright MB, Rydlewicz JA. Efficacy of intra-articular hyaluronic acid injections in knee osteoarthritis. Clinical Orthopaedics and Related Research. 2001 Sep 1;390:173-81.

14. Kusayama Y, Akamatsu Y, Kumagai K, Kobayashi H, Aratake M, Saito T. Changes in synovial fluid biomarkers and clinical efficacy of intra-articular injections of hyaluronic acid for patients with knee osteoarthritis. Journal of experimental orthopaedics. 2014 Dec 1;1(1):16.

15. Salehi-Abari I. 2016 ACR revised criteria for early diagnosis of giant cell (temporal) arteritis. Autoimmune Diseases and Therapeutic Approaches. 2016;3:1-4.

16. Kohn MD, Sassoon AA, Fernando ND. Classifications in brief: Kellgren-Lawrence classification of osteoarthritis. Clinical Orthopaedics and Related Research 2016 Aug; 474(8): 1886-93.

17. Alves TI, Girish G, Kalume Brigido M, Jacobson JA. US of the knee: scanning techniques, pitfalls, and pathologic conditions. Radiographics. 2016 Oct;36(6):1759-75.

18. Gandikota G, Tun M. Ultrasound of the hip in rheumatology. Indian Journal of Rheumatology. 2018 Aug 1;13(5):29-35.

19. Terslev L, D'Agostino MA, Brossard M, Aegerter P, Balint P, Backhaus M, Bruyn GA, Chary-Valckenare I, Filippucci E, Freeston J, Gandjbakhch F. Which knee and probe position determines the final diagnosis of knee inflammation by ultrasound? Results from a European multicenter study. Ultraschall in der Medizin-European Journal of Ultrasound. 2012 Dec;33(07):E173-8.

20. Iagnocco A, Meenagh G, Riente L, Filippucci E, Delle Sedie A, Scire CA, Fulvia C, Montecucco C, Grassi W, Bombardieri S, Guido V. Ultrasound imaging for the rheumatologist XXIX. Sonographic 
assessment of the knee in patients with osteoarthritis. Clinical and Experimental Rheumatology. 2010;28(5):643-6.

21. Kristoffersen H, Torp-Pedersen S, Terslev L, Qvistgaard E, Cato Holm C, Ellegaard K, Bliddal H. Indications of inflammation visualized by ultrasound in osteoarthritis of the knee. Acta radiologica. 2006 Apr;47(3):281-6.

22. Legré-Boyer V. Viscosupplémentation: techniques, indications, résultats: Viscosupplementation: techniques, indications, results. Conférences d'enseignement 2014. 2014Jan1:141-53. Elsevier Masson.

23. D’Agostino MA, Conaghan P, Le Bars M, Baron G, Grassi W, Martin-Mola E, Wakefield R, Brasseur JL, So $A$, Backhaus M, Malaise M. EULAR report on the use of ultrasonography in painful knee osteoarthritis. Part 1: prevalence of inflammation in osteoarthritis. Annals of the rheumatic diseases. 2005 Dec 1;64(12):1703-9.

24. Pelletier JP, Raynauld JP, Abram F, Haraoui B, Choquette D, Martel-Pelletier J. A new non-invasive method to assess synovitis severity in relation to symptoms and cartilage volume loss in knee osteoarthritis patients using MRI. Osteoarthritis and cartilage. 2008 Oct 1;16:S8-13.

\section{Figures}

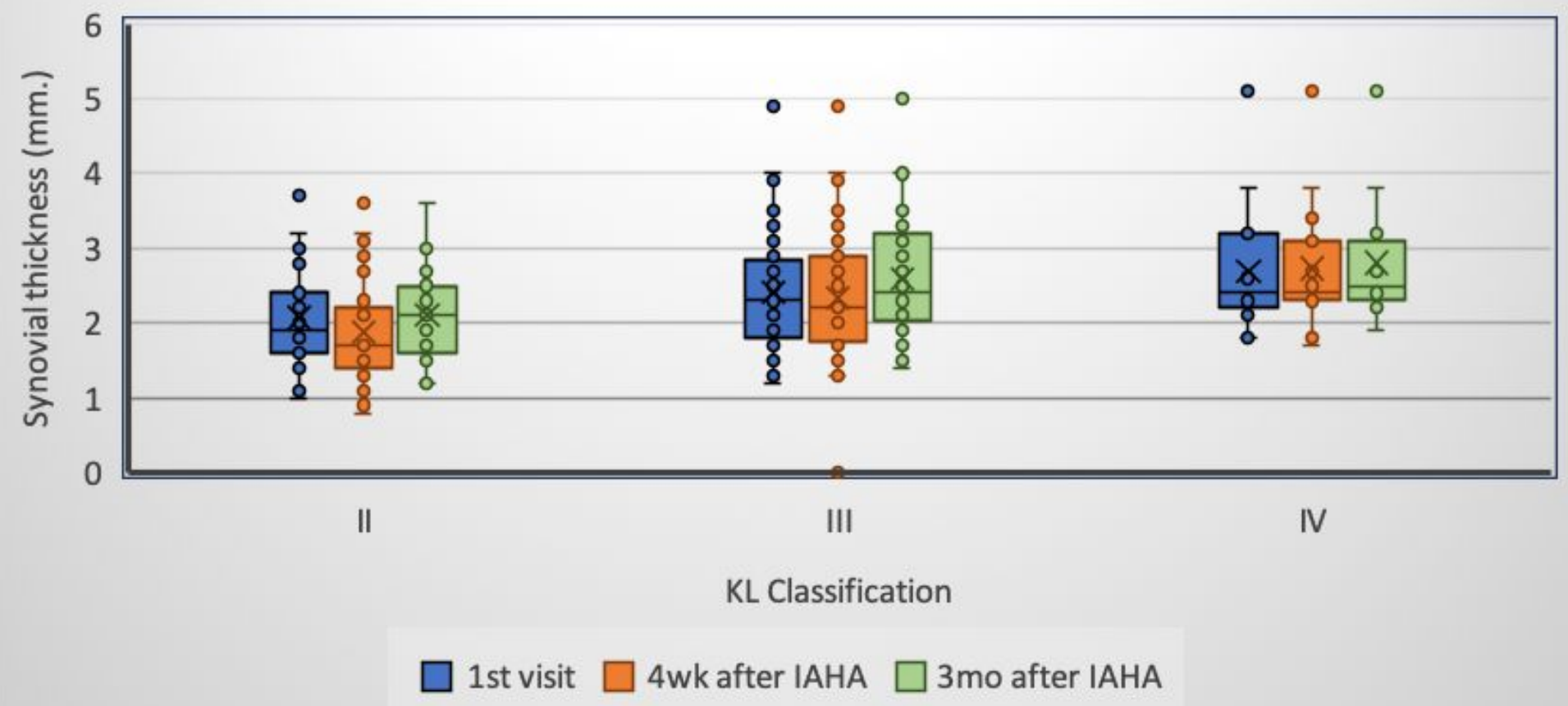

\section{Figure 1}

Synovial thickness in different groups of knee OA 


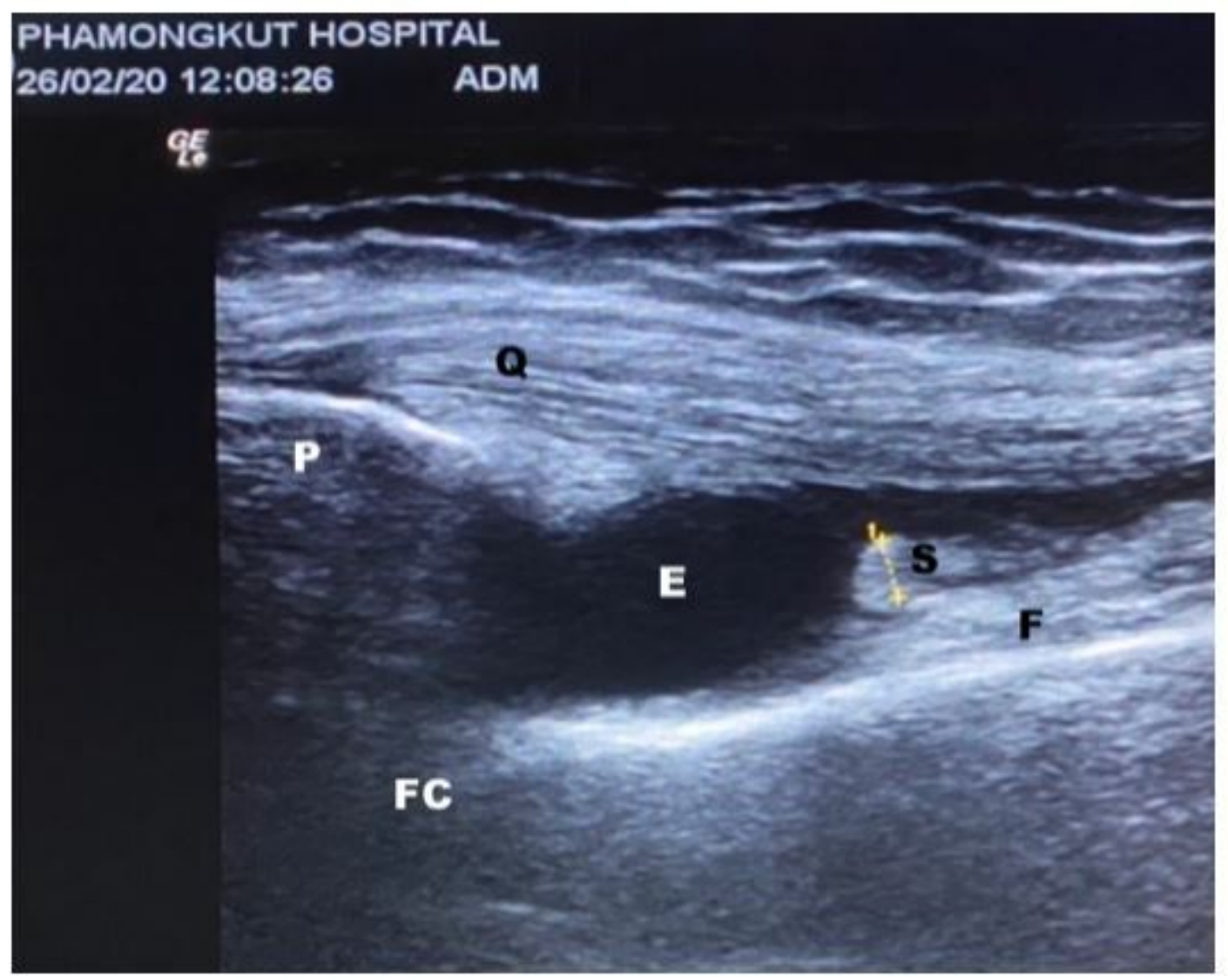

Figure 2

Ultrasonogram imaging and measurement of synovial thickness ( $S=$ synovial hypertrophy, $E=$ effusion, $\mathrm{FC}=$ femoral condyle, $\mathrm{Q}=$ quadriceps, $\mathrm{F}=$ pre-femoral fat pad, and $\mathrm{P}=$ patella)

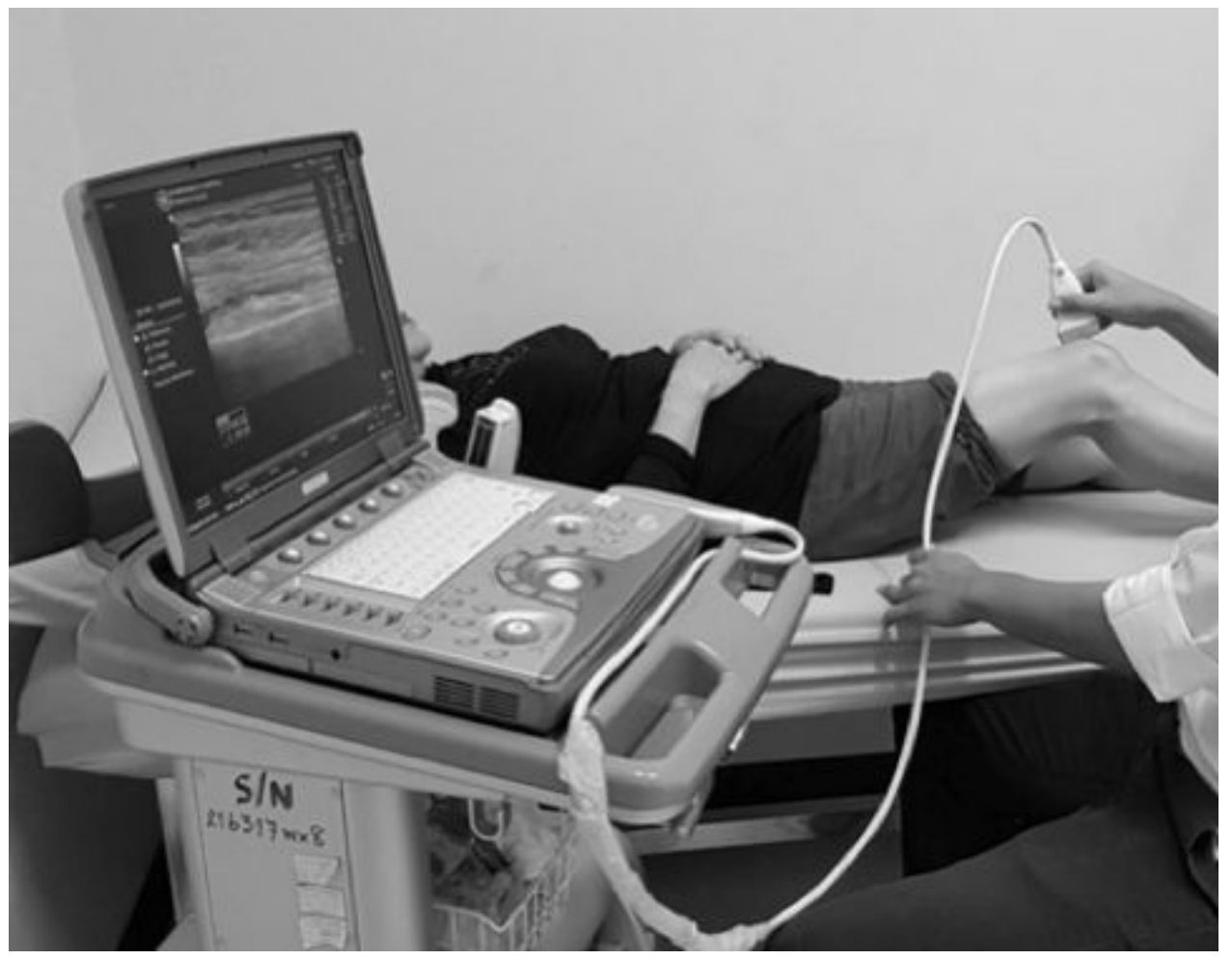

Page $12 / 13$ 
Figure 3

Ultrasonography with mid-line scanning technique using a linear probe 